\title{
ABO Blood Groups and Gastric Ulcer
}

\author{
A. L. MACAFEE \\ From the Department of Pathology, The Queen's University of Belfast.
}

The finding of Aird, Bentall, Mehigan, and Roberts (1954) that there was a strong association between blood group $\mathrm{O}$ and gastric ulcer has been followed by a diversity of results. Many authors, reviewed by Beasley (1960), support the findings, but others found no significant differences between controls and patients with gastric ulcer. The present series adds further support for the association between blood group $O$ and gastric ulcer.

\section{Material}

The data were derived from the case records of 325 in-patients who were treated in the Belfast hospitals during an eight-year period 1953 to 1960 inclusive. There were 199 male and 126 female patients. All patients had a laparotomy with gastrectomy and in all the diagnosis of gastric ulcer was confirmed histologically. All patients were residents of Belfast. The ABO blood groups were known for the complete series.

In order to compare the ABO distributions of the patients with suitable controls it was necessary that patients and controls were drawn from the same population. The ABO blood group distribution was known for a large series $(11,327)$ of current blood donors normally resident in the County Borough of Belfast and these were used as controls. The blood donors' distributions have been used to compute the expected

\section{TABLE I}

DISTRIBUTION OF 325 PATIENTS WITH SIMPLE GASTRIC PEPTIC ULCERATION BY ABO BLOOD GROUPS COMPARED WITH EXPECTED DISTRIBUTION FROM CONTROLS]

\begin{tabular}{|c|c|c|c|}
\hline \multirow{2}{*}{$\begin{array}{l}\text { Blood } \\
\text { Group }\end{array}$} & \multicolumn{2}{|c|}{ Patients } & \multirow{2}{*}{$\begin{array}{l}\text { Controls } \\
\text { Percentage }\end{array}$} \\
\hline & Total Number & Percentage & \\
\hline \multirow[t]{2}{*}{$\begin{array}{l}\mathbf{A} \\
\mathbf{O} \\
\mathbf{B} \\
\mathbf{A B}\end{array}$} & $\begin{array}{r}109 \\
187 \\
24 \\
5\end{array}$ & $\begin{array}{r}33 \cdot 54 \\
57 \cdot 54 \\
7 \cdot 38 \\
1 \cdot 54 \\
\end{array}$ & $\begin{array}{r}37.01 \\
48 \cdot 75 \\
10.85 \\
3.39 \\
\end{array}$ \\
\hline & 325 & $100 \cdot 0$ & $100 \cdot 0$ \\
\hline \multicolumn{4}{|c|}{$x^{2}=13.085 ;$ d.f. $=3 ; 0.01>p>0.001$} \\
\hline
\end{tabular}

Received April 14, 1964. distribution of patients on the hypothesis that patients and controls have similar $\mathrm{ABO}$ distributions.

\section{Results}

Table I shows the ABO distribution of the patients compared with that expected from thei I 1,327 controls. There was a significant $(p>0.05)_{0}^{+}$ difference between the observed and expected distribution $\left(\chi^{2}=13.445 ; \quad 0.01>\mathrm{p}>0.001\right) \cdot \vec{z}$ About $58 \%$ of patients were blood group $O$ in contrast to only about $49 \%$ of the controls. Con- $\frac{\widehat{T}}{\supset}$ sideration of each sex and separate age-group $\overrightarrow{.}$ makes no material difference to this conclusion.

\section{Discussion}

Woolf's (1955) method has been used to compare and combine these data with some of those⿳亠丷厂 from the literature. The result is seen in Table II. $\mathrm{D}$

In London, Iowa, and Belfast the estimated $\stackrel{\varrho}{=}$ incidence of gastric ulcer in persons of bloodo $\overrightarrow{0}$ group $O$ is significantly greater than in those of blood group A. There is no evidence of significant heterogeneity between areas, and estimates of all are validly combined to give an average weighted $\overline{3}$ relative incidence of $I \cdot I 8$. This present series thus:adds further support to the published work show- 3 ing an association between blood group $O$ and gastric ulcer.

\section{Summary}

There were 325 patients suffering from histo- $\frac{D}{0}$ logically proven gastric ulcer who showed a significant excess of blood group $O$. This present $\tilde{N}$ series supports results from other centres.

I wish to acknowledge the help and encouragement 0 of Professor J. H. Biggart who initially suggested the investigation of this problem. I am also very gratefulc to Professor E. A. Cheeseman for his advice and to Mr J. D. Merrett and Mrs J. McCabe for their help.? The physicians and surgeons of the Belfast Hospitals 0 kindly permitted me to examine their case records. I am also grateful to $\mathrm{Dr} M$. C. Huth of the Northern $\mathbb{D}$ Ireland Blood Transfusion Service who provided the $\frac{\odot}{\Phi}$ control data. 
TABLE II

GASTRIC ULCER: RELATIVE INCIDENCE IN PERSONS OF GROUP O COMPARED WITH INCIDENCE OF ONE IN PERSONS OF GROUP A

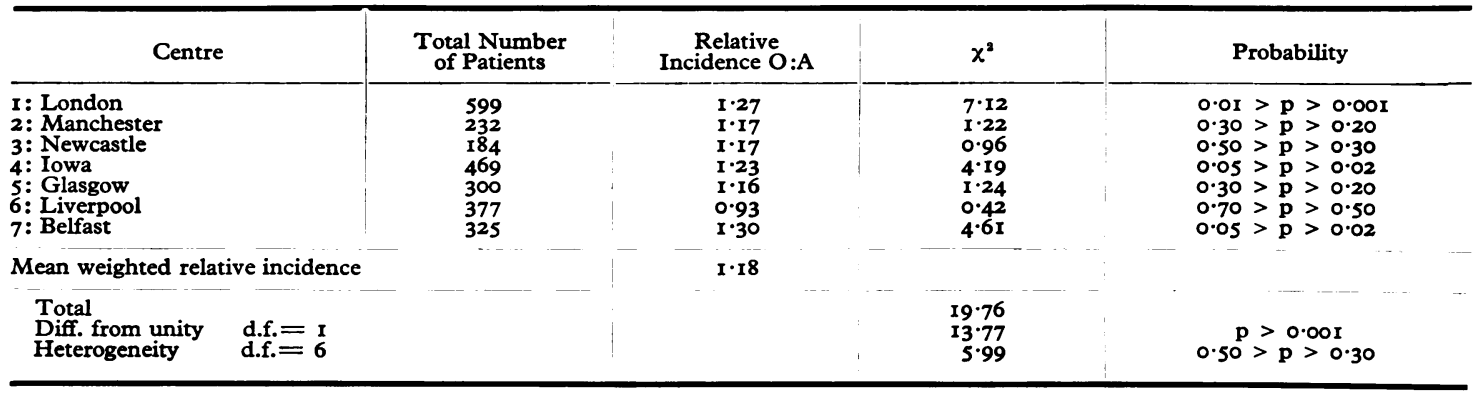

Source of material: 1-3: Aird, et al. (1954).

4: Buckwalter, Wohlwend, Colter, Tidrick, and Knowler (1956).
5: Brown, Melrose, and Wallace (I956).
6: Clarke, Cowan, Edwards, Howel-Evans, McConnell, Woodrow, and Sheppard (I955).
Controls for 1, 2, 3, and 6: Aird, Lee, and Roberts (1960).

\section{REFERENCES}

Aird, I., Bentall, H. H., Mehigan, J. A., and Roberts, J. A. Fraser (1954). The blood groups in relation to peptic ulceration and carcinoma of colon, rectum, breast, and bronchus. Brit. med. f., 2, 315.

$\longrightarrow$, Lee, D. R., and Roberts, J. A. Fraser (I960). ABO blood groups and cancer of oesophagus, cancer of pancreas, and pituitary adenoma. ibid., 1,1163 .

Beasley, W. H. (I960). Blood groups of gastric ulcer and carcinoma. ibid., 1,1167 .
Brown, D. A. P., Melrose, A. G., and Wallace, J. (1956). The blood groups in peptic ulceration. ibid., 2,135 .

Buckwalter, J. A., Wohlwend, E. B., Colter, D. C., Tidrick, R. T., and Knowler, L. A. (1956). Peptic ulceration and ABO blood groups. F. Amer. med. Ass., r62, 1215.

Clarke, C. A., Cowan, W. K., Edwards, J. W., Howel-Evans, A. W., McConnell, R. B., Woodrow, J. C., and Sheppard, P. M. (1955). The relationship of the ABO blood groups to duodenal and gastric ulceration. Brit. med. F., 2, 643 .

Woolf, B. (1955). On estimating the relation between blood group and disease. Ann. hum. Genet., 19, 251. 